\section{At the threshold of consciousness}

\section{K.E.Webster}

The Thalamus. By Edward G. Jones. Plenum: 1985. Pp.935. \$135, £114.09.

SOME 50 years ago, Sir Wilfrid Le Gros Clark described the thalamus as "at the threshold of consciousness". The phrase conveys vividly the peculiarity of an organization common to all vertebrates: the flow of sensory information to the cerebral cortex and basal ganglia (or their homologues) in the forebrain is, with few — and largely peculiar - exceptions, strikingly interrupted in the nuclei of the thalamus. And yet the effects of the destruction of the thalamus, even in human beings, are seemingly either obviously predictable (for example blindness) or spectacularly unpredictable (for example the changes in pain sensibility associated with the thalamic syndrome). This crude summary indicates, I hope, why the thalamus has fascinated so many distinguished neuroscientists for so long.

Nonetheless, this beautifully produced book is the first large-scale monograph on the thalamus to be published since the 1930s. Its scope is wide: it includes an introductory historical chapter - which lends an admirable perspective to the whole - and ranges from cytoarchitecture through synaptology, connectivity, physiology and histo-pharmacology, to ontogeny and comparative studies of the vertebrate thalamus. In general, the functional groups of nuclei are dealt with together. In many cases, when the sources of afferents and the targets of efferents are referred to, the discussion of the organization of the sources and targets is commendably extensive and well-researched: comparable in fact, to that on the subject matter sensu strictu. The reader can thus turn to the book as a useful source of references and informed discussion on, for example, the organization of the cerebral cortex.

The text is very readable, yet exhaustively referenced, and the numerous illustrations are of high quality. The book imparts a clear sense that the overall objective is to explain the significance of the vertebrate thalamus. That, in the last analysis, the account fails in this endeavour is a reflection not so much upon the author as upon the ultimately intractable nature of his subject matter. Professor Jones makes us well aware that, vast as our knowledge may now be, our understanding remains small: a truly allembracing synthesis is as little possible now as it was 50 years ago.

Inevitably, in a book of this size and compass, there are details of interpreta- tion with which one might disagree, or information at the omission of which one might complain. In my view such omissions are virtually always trivial, and represent but minor blemishes on a successful and accomplished work, while the contentious emphases and interpretations are, for me at least, the spice in a generous meal. This book is at once stimulating and useful: the earlier monographs of Le Gros Clark and of Walker have a worthy successor.

K.E. Webster is Professor in the Department of Anatomy and Human Biology, King's College London (KQC), Strand, London WC2R $2 L S$, UK.

\section{Brief encounter}

\section{Irwin Fridovich}

Biochemistry of Dioxygen. By Lloyd L. Ingraham and Damon L. Meyer. Plenum:1985. Pp.287. \$45, £39.13.

This volume, fourth in a series entitled Biochemistry of the Elements, might have had as its subtitle: Once Over Lightly. Dioxygen, its singlet states and reduction products, and the enzymes which produce and act upon them, has been under intense investigation for several decades and is the subject of a vast and rich literature. Unfortunately the authors have tried to cover it all in a small-format book of only 287 pages. They would have been better advised to have chosen some modest fraction of this broad field and to have tilled it more diligently. Probably the cause for the less than satisfactory outcome was faulty planning; if selenium deserved one volume (Vol. 2 in the series), then dioxygen should have commanded at least four volumes.

The collision between the enormity of the subject matter and the paucity of space has yielded a book which does not bear up well under close scrutiny. The results of the past five years of research are almost entirely ignored; illuminating equations, chemical structures and diagrams are too few; typographical errors are numerous; explanations are sometimes so compressed that their import will be opaque to most readers; and the facts stated are sometimes erroneous. Some specific examples are required to give substance to these charges.

Thus, sulphite is prone to oxidation by a free radical chain reaction, but sulphite does not reduce $\mathrm{O}_{2}$ to $\mathrm{O}_{2}^{-}$. The ironcontaining superoxide dismutase of Escherichia coli was once thought to reside in the periplasm, but this claim was withdrawn on the basis of subsequent work. Some evidence for the existence of an essential persulphide in xanthine oxidase was once presented, but more recent work identifies the essential sulphur as a terminal ligand of the molybdenum, which in turn is attached to a novel pterin prosthetic group called molybdopterin; this pterin, whose discovery is the most exciting development of the past decade of study of xanthine oxidase, is nowhere mentioned. D-Amino acid oxidase catalyses the oxidation of the nitroethane anion, not of ethyl nitrate. The chapter on catalases and peroxidases makes no reference to the bacterial catalases, such as the manganese-catalase, and the chapter on "Biological Iron Dioxygen Carriers" fails to mention the Bohr effect and the influence of 2,3-diphosphoglycerate on the oxygen-binding curve of haemoglobin. The cooperativity of dioxygen binding to haemoglobin is discussed but not its physiological significance.

There is much more, but this will suffice. One may sum up the book by saying that the authors tried too much and hence were doomed to fail. We must hope that another attempt by several authors, spread over several volumes, will one day do justice to this important subject.

Irwin Fridovich is James B. Duke Professor of Biochemistry at Duke University Medical Center, Durham, North Carolina 27710, USA.
Tin decline: an abandoned mine, near Lydford, Devon, UK. The picture is taken from the paperback edition of Landscape in Britain, with photographs by Charlie Waite and commentary by Adam Nicolson, to be published in Britain on 24 March by Pavilion.

IMAGE
UNAVAILABLE
FOR
COPYRIGHT
REASONS

